\title{
Dose-Dependent Effects of Barley Cooked with White Rice on Postprandial Glucose and Desacyl Ghrelin Levels
}

\author{
Masae Sakuma, Hisami Yamanaka-Okumura*, Yuko Naniwa, Dai Matsumoto, \\ Megumi Tsunematsu, Hironori Yamamoto, Yutaka Taketani, and Eiji Takeda \\ Department of Clinical Nutrition, Institute of Health Biosciences, University of Tokushima Graduate School, \\ 3-18-15 Kuramoto, Tokushima 770-8503, Japan
}

Received 25 September, 2008; Accepted 20 October, 2008

\begin{abstract}
Summary White rice is an indispensable staple food in Japan, although it is a high glycemic index food. The objective of this study was to estimate how barley cooked with white rice might affect postprandial glucose, insulin and desacyl ghrelin concentrations as well as fullness. The study was conducted in randomized crossover design with nine healthy subjects. Blood glucose, insulin, free fatty acid and desacyl ghrelin concentrations and subjective levels of fullness and hunger were measured for $240 \mathrm{~min}$ after intake of glucose, white rice, $30 \%$ rolled barley (30BAR), 50\% rolled barley (50BAR) and $100 \%$ rolled barley (100BAR) containing $75 \mathrm{~g}$ of available carbohydrate. Postprandial glucose and insulin levels were suppressed by intake of 30BAR, 50BAR and 100BAR comparing with those of white rice. Area under the curves of plasma glucose and insulin concentrations was reduced by barley intake in a dosedependent manner. Although plasma desacyl ghrelin levels decreased postprandially, the degree of reduction was suppressed by barley intake in a dose-dependent manner. Postprandial desacyl ghrelin levels can be a sensitive biomarker of carbohydrate metabolism. The combination of white rice with barley plays a beneficial role in preventing and treating type 2 diabetes, obesity and other metabolic diseases.
\end{abstract}

Key Words: white rice, barley, insulin, desacyl ghrelin, fullness

\section{Introduction}

Recently, the number of cases of diabetes has rapidly increased worldwide, prompting renewed efforts to implement primary prevention measures. The glycemic index (GI) is a ranking of carbohydrates based on their immediate effects on blood glucose levels [1]. Epidemiologic studies demonstrated that the GI of the diet might be an important factor in preventing type 2 diabetes [2-4]. Japanese and other Asian cuisines, combining white rice (staple food) with another dish, are characterized by low fat intake. A low-fat diet has beneficial effects for the prevention or

\footnotetext{
*To whom correspondence should be addressed

Tel: +81-88-633-9595 Fax: +81-88-633-7094

E-mail: yamanaka@nutr.med.tokushima-u.ac.jp
}

treatment of diseases related to insulin resistant syndrome [5]. However, white rice belongs to the group of high GI foods [6]. A previous study indicated that the relative glycemic effects of mixed meals are mainly influenced by GI of the staple food [7]. Furthermore, replacement of carbohydrate in the dish with a low GI diet improved early insulin secretion compared with a high GI diet in metabolic syndrome subjects [8]. These data suggest that staple carbohydrate-rich foods with low GI are needed for the prevention of diabetes. Several studies investigating the effects of mixtures of high-GI and low-GI grains have been reported, but most of these investigations used bread $[9,10]$, rather than white rice, as the test meal. Barley is a typical low GI food, but it is difficult to ingest barley alone because its texture is very hard. Although white rice is sometimes cooked with $20-30 \%$ barley, which can be easily ingested, it is unclear whether this combination affects postprandial 
glucose metabolism.

Ghrelin is one of the hormones involved in controlling body weight, insulin secretion and appetite regulation. The plasma concentration of ghrelin is known to gradually increase before a meal and then decrease immediately after a meal [11-13]. Ghrelin has two major molecular forms: acyl ghrelin and desacyl ghrelin [14]. Plasma desacyl ghrelin accounts for more than $90 \%$ of total circulating ghrelin [14, 15], whereas acyl ghrelin is relatively unstable and is rapidly converted into desacyl ghrelin or smaller fragments. This study was undertaken to clarify the effect of barley mix with white rice on postprandial plasma glucose, insulin and desacyl ghrelin levels in healthy subjects.

\section{Experimental Procedures}

\section{Subjects}

Six healthy men and 3 healthy women were recruited in this study. The study was performed after obtaining written

Table 1. Characteristics of the subjects

\begin{tabular}{lc}
\hline Characteristics & Values \\
\hline F/M & $3 / 6$ \\
Age (years) & $26.7 \pm 1.1$ \\
Body weight $(\mathrm{kg})$ & $61.1 \pm 2.8$ \\
BMI $\left(\mathrm{kg} / \mathrm{m}^{2}\right)$ & $22.0 \pm 0.7$ \\
Body fat ratio $(\%)$ & $18.5 \pm 2.6$ \\
Triacylglycerol $(\mathrm{mg} / \mathrm{dl})$ & $77.0 \pm 10.5$ \\
Total cholesterol (mg/dl) & $162.9 \pm 8.2$ \\
HDL cholesterol (mg/dl) & $55.6 \pm 2.3$ \\
Fasting plasma glucose (mmol/l) & $4.9 \pm 0.1$ \\
HbAlc (\%) & $4.8 \pm 0.1$ \\
BUN (mg/dl) & $11.3 \pm 0.8$ \\
Creatinine (mg/dl) & $0.8 \pm 0.05$ \\
AST (IU/l) & $15.6 \pm 0.8$ \\
ALT (IU/l) & $15.0 \pm 2.1$ \\
\hline
\end{tabular}

Values are means \pm SEM.

HDL, high density lipoprotein; BUN, blood urea nitrogen; AST, aspartate aminotransferase; ALT, alanine aminotransferase. informed consent from all of the subjects, and was approved by the Ethics Committee of the University of Tokushima. The clinical and biological characteristics of the subjects are shown in Table 1 . The mean values \pm SEM of age and body mass index (BMI) were $26.7 \pm 1.1$ years and $22.0 \pm 0.7$ $\mathrm{kg} / \mathrm{m}^{2}$, respectively.

\section{Study protocol}

The design of this experiment was a randomized and crossover study. The experiment was conducted so that each test day was separated by a washout period of 7 days. All the subjects were asked to avoid heavy exercise and intake of alcohol $24 \mathrm{~h}$ before the day of the study. The subjects were instructed to eat and drink the same prescribed foods at $2000 \mathrm{~h}$ before a test day. After an overnight fast, venous blood samples were collected at $0840 \mathrm{~h}$ and each subject was asked to complete a short questionnaire rating their appetite using a visual analog scale (VAS). The subjects were provided with their test meals (breakfast) at $0900 \mathrm{~h}$ and were required to consume each test meal within $20 \mathrm{~min}$. Blood samples were collected at 0 (i.e., immediately before) and $30,45,60,90,120,180$ and $240 \mathrm{~min}$ after the meal. The blood samples were used to analyze glucose, insulin, free fatty acid (FFA) and desacyl ghrelin levels.

\section{Test meals}

Five different test meals were used: glucose (GL), white rice (WR), 30\% rolled barley (30BAR), 50\% rolled barley (50BAR) and $100 \%$ rolled barley (100BAR) containing $75 \mathrm{~g}$ available carbohydrate. White rice and rolled barley were boiled, and then served. The amounts of available carbohydrate in 30BAR were $52.5 \mathrm{~g}$ and $22.5 \mathrm{~g}$, and in 50BAR were $37.5 \mathrm{~g}$ and $37.5 \mathrm{~g}$ from $\mathrm{WR}$ and BAR, respectively (Table 2). Except for GL, all other test meals were made up in water to give a final total volume of $650 \mathrm{ml}$.

\section{Visual analogue scores (VAS)}

VAS was used to measure subjective feelings of hunger and fullness. VAS consisted of $100 \mathrm{~mm}$ vertical lines with short questionnaire anchored at each end that expressed the most positive or most negative sensation. Subjects drew a

Table 2. Energy and macronutrient composition of the test meals

\begin{tabular}{|c|c|c|c|c|c|}
\hline & GL & WR & 30BAR & 50BAR & 100BAR \\
\hline Meal volume (ml) & 225 & 375 & 398 & 413 & 450 \\
\hline Water volume (ml) & - & 275 & 252 & 237 & 200 \\
\hline Total volume (ml) & 225 & 650 & 650 & 650 & 650 \\
\hline Energy $(\mathrm{kJ})$ & 1255 & 1435 & 1460 & 1477 & 1515 \\
\hline Protein $(\mathrm{g})$ & 0.0 & 4.6 & 5.4 & 5.9 & 7.2 \\
\hline Fat $(\mathrm{g})$ & 0.0 & 0.9 & 1.1 & 1.3 & 1.7 \\
\hline Available carbohydrate (g) & 75.0 & 75.0 & 75.0 & 75.0 & 75.0 \\
\hline Dietary fiber $(\mathrm{g})$ & 0.0 & 0.5 & 3.2 & 4.9 & 9.2 \\
\hline
\end{tabular}


horizontal line at the point on the vertical line that corresponded to their sensation.

\section{Analysis methods}

Plasma and serum samples were separated and stored at $-80^{\circ} \mathrm{C}$ until use. Plasma glucose levels were measured by an enzymatic method (hexokinase method) (Sino-test, Tokyo, Japan). Serum insulin levels were measured by chemiluminescent enzyme immunoassay (EIKEN, Tokyo, Japan). Serum FFA levels were measured enzymatically (EIKEN, Tokyo, Japan). Plasma desacyl ghrelin levels were measured by enzyme linked immunosorbent assay (Mitsubishi Kagaku Iatoron, Tokyo, Japan). The incremental area under the curve (AUC) for plasma glucose and insulin were calculated for a 240-min period after each test meal.

\section{Statistical analysis}

Data are shown as mean \pm SEM. Firstly, the statistical difference was determined by 1-way ANOVA, with Fisher's protected least significant difference as a posthoc test to compare 3 test meals (GL, WR and 100BAR). Secondly, the statistical difference was determined to compare white rice with combining white rice and barley in varying proportions. Data of 30BAR and 50BAR were compared with WR respectively. Groups were compared for differences using Student's $t$ test for paired comparisons. Correlation was calculated using stepwise linear regression by combining data from the 4 groups. Note that GL was not included in this analysis because this test meal had a different volume. All of the statistical analyses were performed with the Stat View 5.0 (SAS Institute, Inc., Cary, NC). $p$ value less than 0.05 was considered significant in all analyses.

\section{Results}

Effects of GL, WR and 100BAR intake on postprandial glucose, insulin and FFA levels

Plasma glucose levels at 30, 45 and $60 \mathrm{~min}$ in 100BAR were significantly lower than in GL $(p<0.01 ; 30$ and $45 \mathrm{~min}$, $p<0.05 ; 60 \mathrm{~min})$ and WR $(p<0.01 ; 45 \mathrm{~min}, p<0.05 ; 30$ and $60 \mathrm{~min}$ ). No differences were observed between GL and WR (Fig. 1a). Serum insulin levels increased after each meal reaching a peak value at $45 \mathrm{~min}$ for GL and WR, and at $30 \mathrm{~min}$ for 100BAR. Serum insulin levels for 100BAR at $30-120 \mathrm{~min}$ were significantly lower than for GL $(p<0.01$; $45,60,90$ and $120 \mathrm{~min}, p<0.05 ; 30 \mathrm{~min}$ ). At 60 and $90 \mathrm{~min}$ serum insulin levels for 100BAR were significantly lower than those in WR $(p<0.05$, respectively). Serum insulin level at $60 \mathrm{~min}$ for WR was markedly lower than for GL $(p<0.05)$ (Fig. 1b). Serum FFA levels for 100BAR fell more slowly than for GL and WR. At 45 and 120 min serum FFA levels for 100BAR were significantly higher than for $\mathrm{GL}(p<0.05$; respectively), and significantly higher than GL and WR at
$180 \min (p<0.01$; respectively). Serum FFA level for GL quickly increased and returned to fasting level at $240 \mathrm{~min}$, and were significantly higher than those for WR and BAR $(p<0.01$; respectively) (Fig. 1c).

In the postprandial early stage (0-30 and 0-60 min), plasma glucose AUCs for 100BAR were significantly lower than those for GL $(p<0.01)$ and WR $(p<0.05)$. At $0-120$, 0-180 and 0-240 min, plasma glucose AUCs tended to be lower for 100BAR compared to those for GL and WR, although this observation was not statistically significant (Fig. 1d). For 100BAR, serum insulin AUCs were significantly lower than those for GL at all time periods $(0-30$, $0-60,0-120,0-180,0-240 \mathrm{~min})(p<0.01)$. At $0-30,0-60$, $0-120$ and $0-180 \mathrm{~min}$, serum insulin AUCs for WR were significantly lower than those for GL $(p<0.05 ; 0-30,0-60$ and $0-180 \mathrm{~min}, p<0.01 ; 0-120 \mathrm{~min})$. Also, serum insulin AUCs at $0-120$ and $0-180 \mathrm{~min}$ for 100 BAR were significantly lower than those for WR $(p<0.01$; respectively) (Fig. 1e).

Dose-dependent effects of barley intake on postprandial glucose, insulin and FFA levels

Plasma glucose levels for 30BAR and 50BAR increased more slowly than for WR. Indeed, the plasma glucose level at $45 \mathrm{~min}$ for 50BAR and 30BAR was significantly lower $(p<0.05)$ or lower $(p=0.07)$ than that for WR, respectively (Fig. 2a). Serum insulin levels increased after each meal, reaching a peak value at either $45 \mathrm{~min}$ for WR or at $30 \mathrm{~min}$ for 30BAR and 50BAR. Serum insulin levels for 30BAR and 50BAR immediately dropped from peak values, and were significantly lower than that for WR at $60 \min (p<0.05$; respectively) (Fig. 2b). Serum FFA levels for 50BAR fell more slowly than those for WR; see values at 120 and $180 \mathrm{~min}$ in Fig. 2c $(p<0.05$; respectively). The plasma glucose AUCs and insulin AUCs were slightly lower for the 30BAR and 50BAR groups compared to the WR group, although these differences were not statistically significant (Fig. 2d, e).

Effects of GL, WR, 30BAR, 50BAR and 100BAR intake on postprandial desacyl ghrelin levels

Postprandial plasma desacyl ghrelin levels after ingestion of 100BAR remained unchanged from the fasting level. By contrast, postprandial plasma desacyl ghrelin levels after intake of GL and WR were markedly suppressed between 30 and $180 \mathrm{~min}$. Specifically, at $60 \mathrm{~min}$ the plasma desacyl ghrelin level for WR was lower than for 100BAR $(p<0.05)$; at $120 \mathrm{~min}$, plasma desacyl ghrelin for GL was lower than for WR $(p<0.05)$ (Fig. 3a). The degree of reduction in the level of plasma desacyl ghrelin was mirrored by the postprandial insulin concentration but not by the glucose concentration. 
a
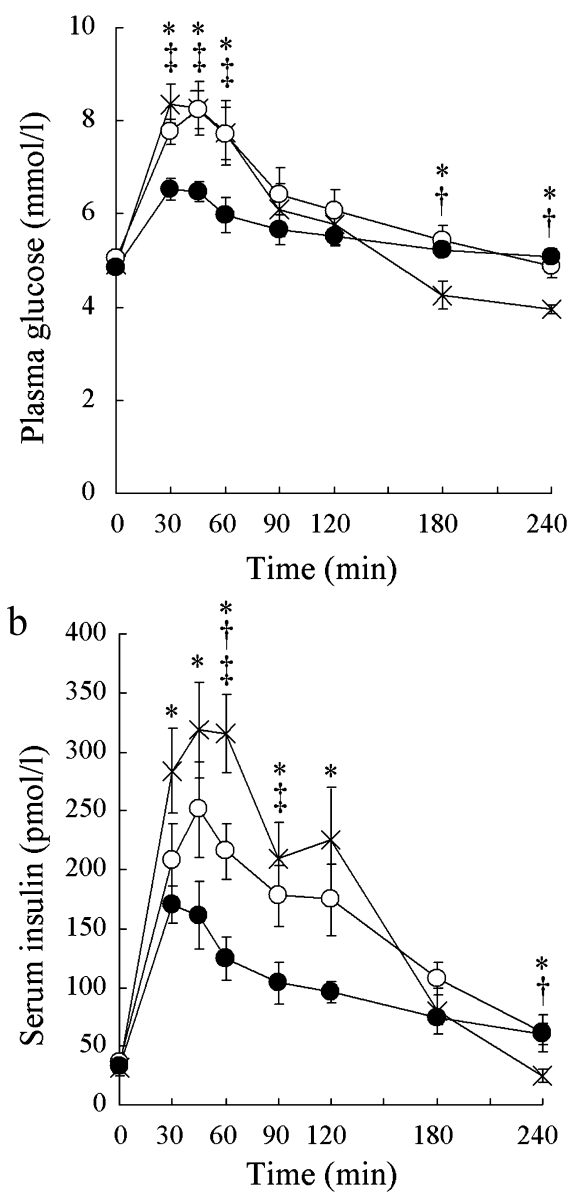

C



d

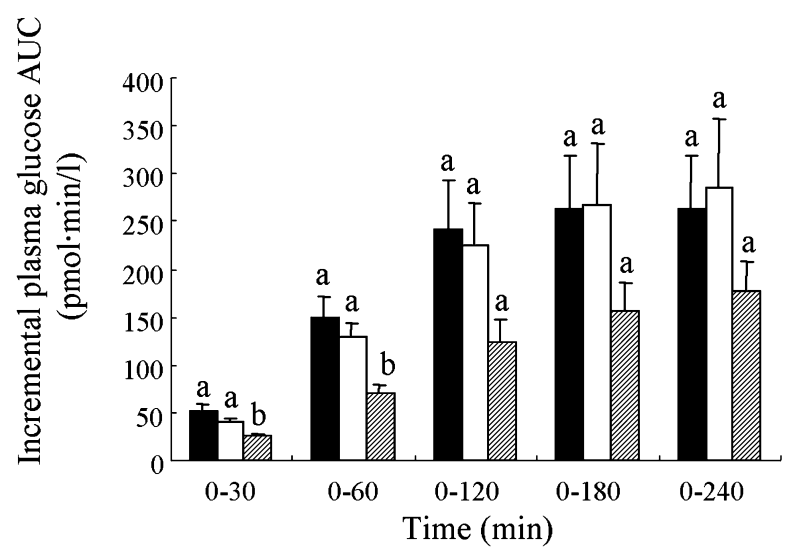

e



Fig. 1. Postprandial plasma glucose (a), serum insulin (b) and serum free fatty acid (c) levels and incremental plasma glucose AUC (d) and serum insulin AUC (e) after ingestion of the 3 test meals (glucose, white rice, barley). X, glucose (GL); open circle, white rice (WR); closed circle, $100 \%$ barley (100BAR). Black bar, glucose (GL); white bar, white rice (WR); hatched bar, 100\% barley (100BAR). Mean values with their standard errors. $* p<0.05$, GL vs $100 \mathrm{BAR} ; t p<0.05$, GL vs WR; $₫ p<0.05$, 100BAR vs WR. Bars in the same panel with different letters are significantly different, $p<0.05$.

\section{Fullness and hunger}

Peak fullness scores occurred $30 \mathrm{~min}$ after each test meal. The peak score for 100BAR was significantly higher than for GL $(p<0.05)$. Fullness score at 180 and $240 \mathrm{~min}$ after ingestion of $100 \mathrm{BAR}$ was significantly higher than after ingestion of GL and WR at the corresponding time points $(p<0.01$; respectively). Fullness scores at $240 \mathrm{~min}$ after intake of GL and WR returned to fasting level values, but remained above fasting level for 100BAR (Fig. 4a). Fullness

score at $45 \mathrm{~min}$ for 50BAR was significantly higher than for WR and 30BAR $(p<0.05$; respectively). For 30BAR and 50BAR, high fullness scores at 180 and $240 \mathrm{~min}$ were significantly higher than for WR $(p<0.05 ; 180 \mathrm{~min}, p<0.01$; $240 \mathrm{~min}$ ) (Fig. 4b). Hunger scores showed reverse patterns of fullness scores (Fig. 4c, d).

\section{Correlation}

Significant variables were entered into a stepwise linear 

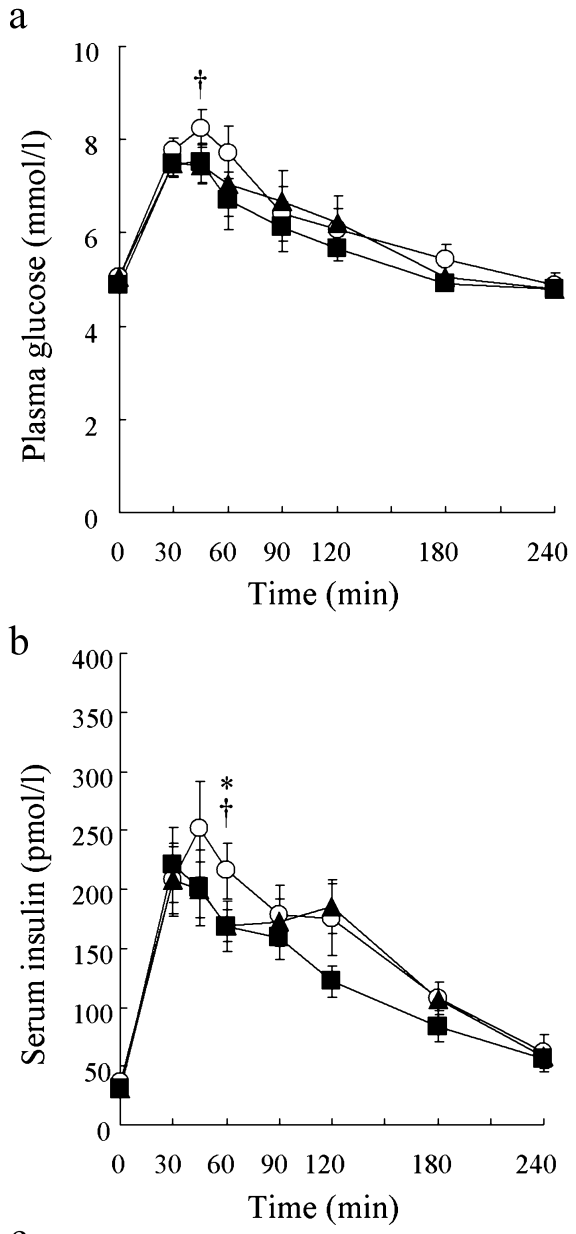

$\mathrm{C}$

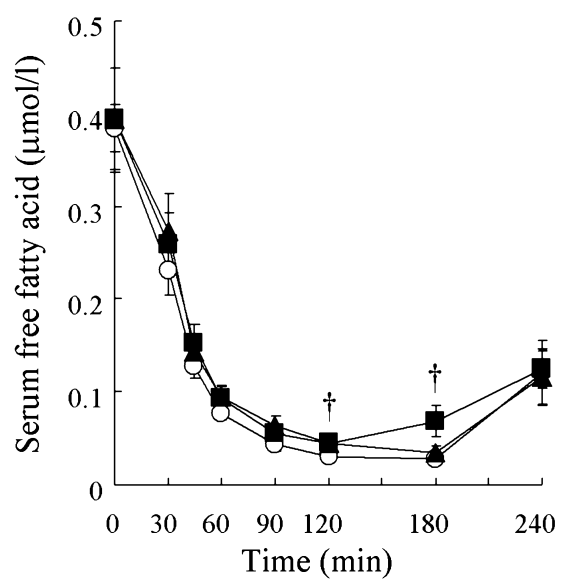

regression model in which the difference from baseline in plasma glucose levels ( $\Delta$ plasma glucose), serum insulin levels ( $\Delta$ serum insulin) and fullness scores ( $\Delta$ fullness) were used as independent variables and difference from baseline in desacyl ghrelin levels ( $\Delta$ plasma desacyl ghrelin) were used as a dependent variable. This analysis revealed that $\Delta$ serum insulin was an independent predictor of $\Delta$ plasma desacyl ghrelin ( $\Delta$ plasma desacyl ghrelin $=65.877-$ $3.886 * \Delta$ serum insulin, $\left.r^{2}=0.074, p<0.0001\right)$. d

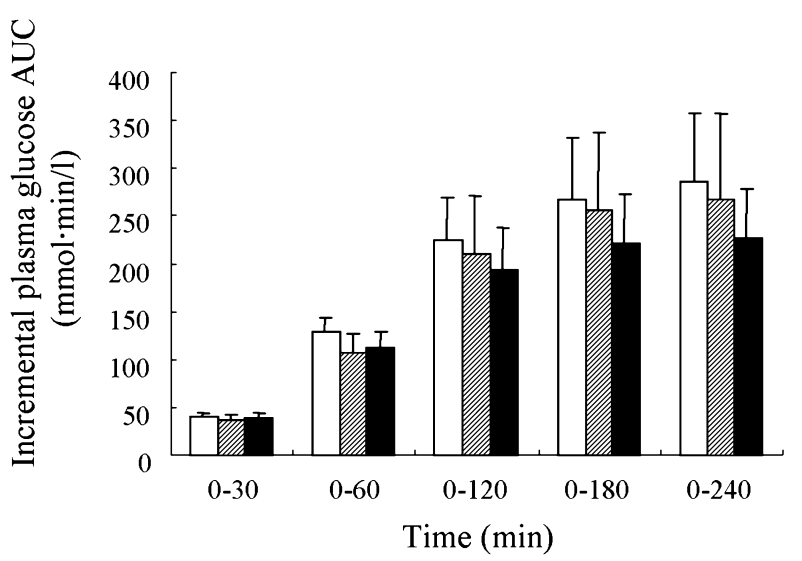

e

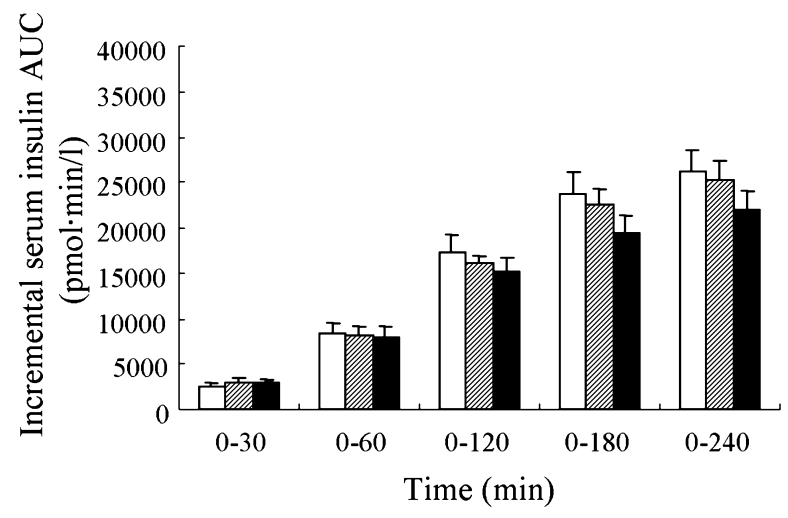

Fig. 2. Postprandial plasma glucose (a), serum insulin (b) and serum free fatty acid (c) levels and incremental plasma glucose AUC (d) and serum insulin AUC (e) after ingestion of the 3 test meals (white rice, 30\% barley, 50\% barley). Open circle, white rice (WR); closed triangle, 30\% barley (30BAR); closed square, $50 \%$ barley (50BAR). White bar, white rice (WR); hatched bar, 30\% barley (30BAR); black bar, $50 \%$ barley (50BAR). ${ }^{*} p<0.05$, WR vs 30BAR; $\uparrow p<0.05$, WR vs 50BAR. Mean values with their standard errors.

\section{Discussion}

In this study, plasma glucose level at $45 \mathrm{~min}$ for 50BAR and 30BAR was significantly lower or lower, and serum insulin levels for 50BAR and 30BAR were significantly lower than that for WR at $60 \mathrm{~min}$. Because viscous fibers have been shown to reduce postprandial glucose and insulin levels [16-18], these effects might be due to the viscous fiber component of barley. Among the various grains, barley 
a

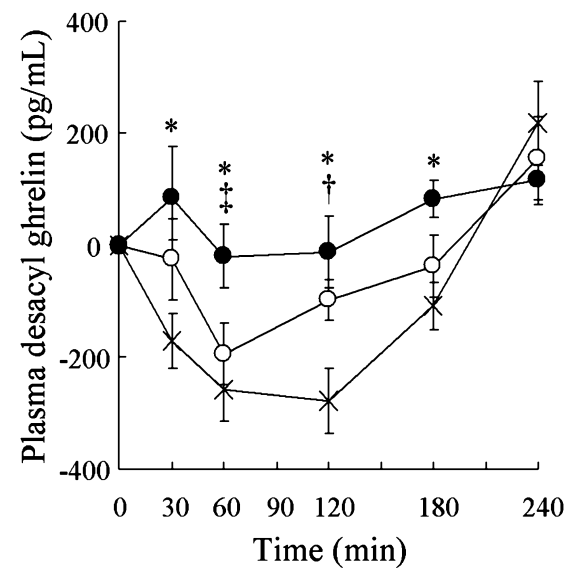

b

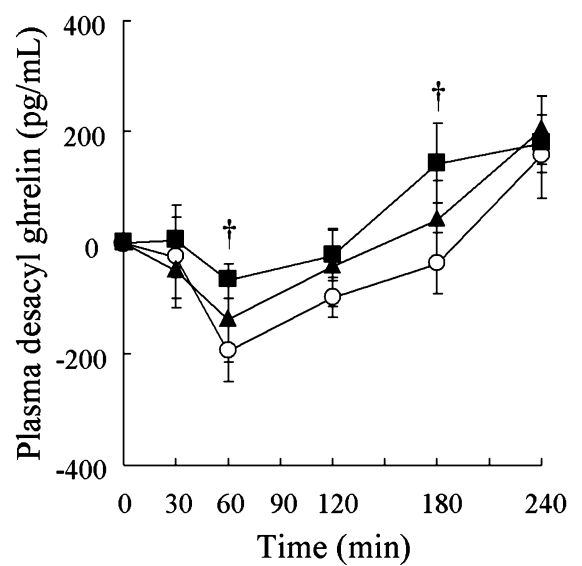

Fig. 3. Postprandial plasma desacyl ghrelin level after ingestion of glucose, white rice, $100 \%$ barley (a), and white rice, $30 \%$ barley, $50 \%$ barley (b). X, glucose (GL); open circle, white rice (WR); closed circle, $100 \%$ barley (100BAR). ${ }^{*} p<0.05$, GL vs 100BAR; $\uparrow p<0.05$, GL vs WR; $₫ p<0.05,100 \mathrm{BAR}$ vs WR. Open circle, white rice (WR); closed triangle, 30\% barley (30BAR); closed square, $50 \%$ barley (50BAR). ${ }^{*} p<0.05$, WR vs $30 \mathrm{BAR} ; \nmid p<0.05$, WR vs 50BAR. Mean values with their standard errors.

is highly viscous in character. Indeed, the viscosity of barley is mainly derived from the $\beta$-glucan content [19]. $\beta$-glucan has been reported to suppress postprandial glucose levels in a dose-dependent manner [20]. A possible mechanism to explain these results might involve delayed or reduced carbohydrate absorption from the gut [21]. The plasma glucose AUCs and insulin AUCs were not statistically significant for the 30BAR and 50BAR compared to the WR. Because it is calculated for the total amount of increase, AUC is difficult to detect the difference with each time point.

In most previous studies using a mixture of high-GI and low-GI grains, the glucose and insulin levels were suppressed compared with those of high-GI when more than $50 \%$ of low-GI grain was used $[9,10]$. Furthermore, the addition of toppings to a carbohydrate-rich food had the effect of reducing the glycemic response [22-24]. The effect was particularly notable for high GI carbohydrate-rich food. The GI of white rice is higher than that of wheat flour bread, barley flour bread or barley porridge [6, 25], which were used as high-GI grains in previous studies $[9,10]$. In this study, the combination of white rice and barley and even 30BAR, showed a definite effect on the suppression of postprandial insulin peak value. And it tended to suppress of postprandial glucose peak value. By contrast, the effect of the combination of white rice and pre-germinated brown rice was not observed [26]. This finding might be explained by the higher GI of brown rice compared with that of barley [27]. Therefore, it is conceivable that GI values and combination rates of each food could be important factors in terms of this phenomenon.
The insulin level peaked earlier and fell more rapidly for 30BAR, 50BAR and 100BAR than for the GL and WR group of subjects. Because the rise in plasma glucose for 30BAR, 50BAR and 100BAR was smaller than for GL and WR, an excessive amount of insulin secretion might be suppressed. Also, it was reported that intake of cereal fibers accelerated the response of the acute glucose-dependent insulinotropic polypeptide (GIP) and insulin response, result in the reduction of postprandial glucose and insulin values the following day [28]. Repeated lower postprandial insulinemic responses may prevent the onset of type 2 diabetes by preventing damage to the $\beta$ cell function. Recovery of $\beta$ cell function or a decrease in insulin resistance will improve early insulin secretion over the long term in patients with type 2 diabetes [29].

We also studied the effect of the ingestion of a carbohydrate-enriched breakfast on the plasma ghrelin level. Percentage change in ghrelin concentration between 30 and $180 \mathrm{~min}$ were negatively correlated with the percentage change in insulin but not with the observed changes in glucose level [30]. Insulin levels after ingestion of a high fiber meal were lower than those after ingestion of a low fiber meal. Furthermore, postprandial reductions of desacyl ghrelin levels were suppressed after intake of a high fiber meal. A stepwise linear regression model revealed that plasma desacyl ghrelin levels were predictors of serum insulin levels but not of plasma glucose levels. In contrast, an arabinoxylan fiber-enriched meal affects serum ghrelin levels but not postprandial insulin responses in healthy subjects [31]. These apparently conflicting results might be due to differences in the amount of carbohydrate used in 




b

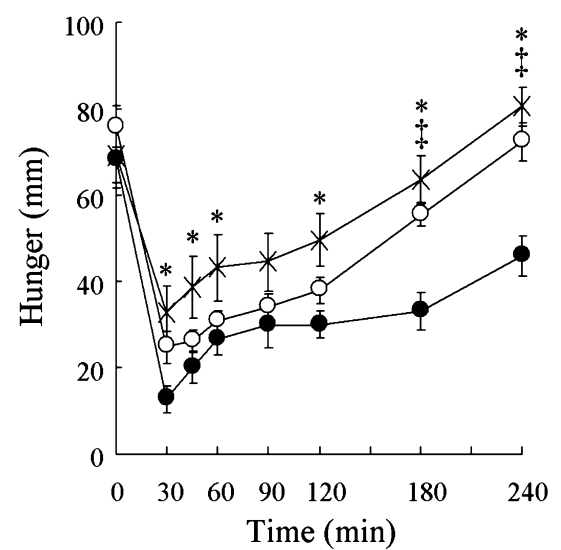

C
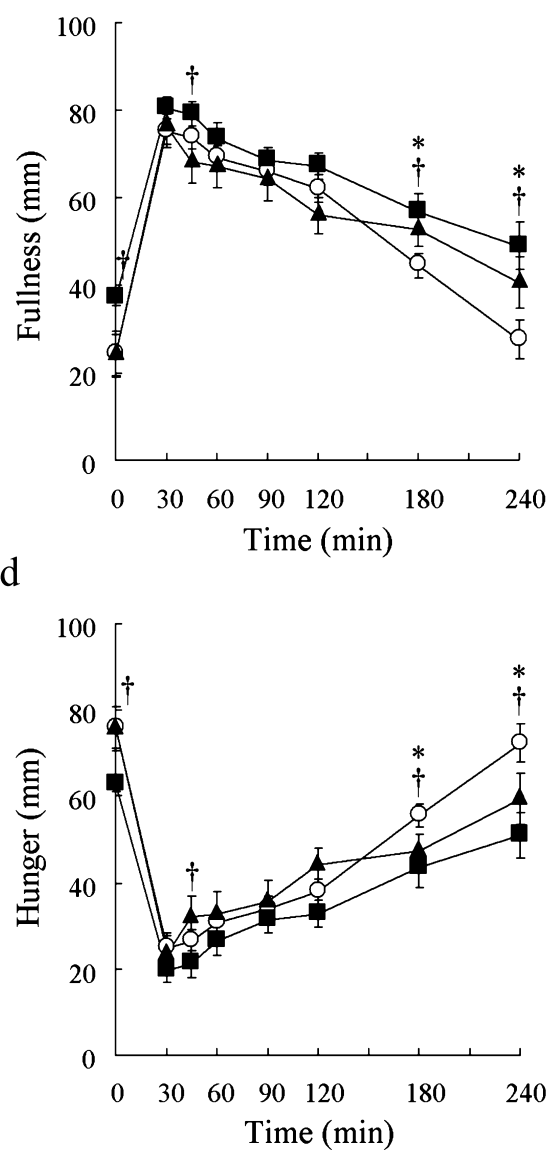

Fig. 4. Postprandial fullness after ingestion of glucose, white rice, $100 \%$ barley (a), white rice, 30\% barley, $50 \%$ barley (c), and postprandial hunger after ingestion of glucose, white rice, $100 \%$ barley (b), white rice, $30 \%$ barley, $50 \%$ barley (d). X, glucose (GL); open circle, white rice (WR); closed circle, 100\% barley (BAR). * $p<0.05$, GL vs 100BAR; $\uparrow p<0.05$, GL vs WR; $\vdots p<0.05,100 \mathrm{BAR}$ vs WR. Open circle, white rice (WR); closed triangle, 30\% barley (30BAR); closed circle, 50\% barley (50BAR). ${ }^{*} p<0.05$, WR vs $30 \mathrm{BAR} ; \dagger p<0.05$, WR vs $50 \mathrm{BAR}$. Mean values with their standard errors.

each study (i.e., $50 \mathrm{~g}$ in previous study compared with $75 \mathrm{~g}$ in our study). Therefore, postprandial desacyl ghrelin levels can act as a sensitive biomarker for the degree of postprandial carbohydrate metabolism.

Intake of 30BAR, 50BAR and 100BAR resulted in prolonged postprandial fullness and in a less pronounced reduction of desacyl ghrelin level compared with the WR group. These findings are consistent with previous work, which concluded postprandial satiety is maintained for longer after intake of a high fiber meal compared to a low fiber meal [32]. There are several inconsistent reports between postprandial ghrelin levels and fullness and satiety. Ghrelin responds rapidly and dose-dependently to carbohydrate intake and is positively correlated with subjective measures of hunger and negatively correlated with fullness [30]. In contrast, postprandial alterations of ghrelin level seem not to play an important role in the acute regulation of satiety $[33,34]$. Furthermore, conflicting reports suggest intracerebroventricular administration of desacyl ghrelin to rats can result in either increased [35] or decreased [36, 37] food intake. Thus, the relationship between postprandial ghrelin level and fullness is still obscure and needs to be clarified in further studies. However, it is important to keep in mind that prolonged fullness after intake of 30BAR, 50BAR and 100BAR may induce a reduction of energy intake and improve glucose metabolism.

In conclusion, results from the present study suggest that the combination of white rice with barley plays a beneficial role in the prevention and treatment of type 2 diabetes, obesity and other metabolic diseases.

\section{Acknowledgments}

This work was supported by Grants-in-Aid for Scientific Research and Knowledge Cluster Initiative from the Ministry of Education, Culture, Sports, Science and a grant obtained 
from the Ministry of Agriculture, Forestry, Fisheries of Japan and Technology in Japan (for H.Y-O., E.T.), and from the 21th Century COE Program, Human Nutritional Science on Stress Control in The University of Tokushima Graduate School Tokushima, Japan.

\section{Abbreviations}

GI, glycemic index; BMI, body mass index; VAS, visual analog scale; FFA, free fatty acid; GL, glucose; WR, white rice; 30BAR, 30\% rolled barley; 50BAR, 50\% rolled barley; 100BAR, 100\% rolled barley; AUC, area under the curve; HDL, high density lipoprotein; BUN, blood urea nitrogen; AST, aspartate aminotransferase; ALT, alanine aminotransferase.

\section{References}

[1] Jenkins, D.J., Wolever, T.M., Taylor, R.H., Barker, H., Fielden, H., Baldwin, J.M., Bowling, A.C., Newman, H.C., Jenkins, A.L., and Goff, D.V.: Glycemic index of foods: a physiological basis for carbohydrate exchange. Am. J. Clin. Nutr., 34, 362-366, 1981.

[2] Salmerón, J., Ascherio, A., Rimm, E.B., Colditz, G.A., Spiegelman, D., Jenkins, D.J., Stampfer, M.J., Wing, A.L., and Willett, W.C.: Dietary fiber, glycemic load, and risk of NIDDM in men. Diabetes Care, 20, 545-550, 1997.

[3] Meyer, K.A., Kushi, L.H., Jacobs, D.R., Slavin, J., Sellers, T.A., and Folsom, A.R.: Carbohydrates, dietary fiber, and incident type 2 diabetes in older women. Am. J. Clin. Nutr., 71, 921-930, 2000.

[4] Murakami, K., Sasaki, S., Takahashi, Y., Okubo, H., Hosoi, Y., Horiguchi, H., Oguma, E., and Kayama, F.: Dietary glycemic index and load in relation to metabolic risk factors in Japanese female farmers with traditional dietary habits. Am. J. Clin. Nutr., 83, 1161-1169, 2006.

[5] Bloomgarden, Z.T.: The 1st World Congress on the Insulin Resistance Syndrome. Diabetes Care, 27, 602-609, 2004.

[6] Sugiyama, M., Tang, A.C., Wakaki, Y., and Koyama, W.: Glycemic index of single and mixed meal foods among common Japanese foods with white rice as a reference food. Eur. J. Clin. Nutr, 57, 743-752, 2003.

[7] Collier, G.R., Wolever, T.M., Wong, G.S., and Josse, R.G.: Prediction of glycemic response to mixed meals in noninsulindependent diabetic subjects. Am. J. Clin. Nutr., 44, 349-352, 1986.

[8] Laaksonen, D.E., Toppinen, L.K., Juntunen, K.S., Autio, K., Liukkonen, K.H., Poutanen, K.S., Niskanen, L., and Mykkänen, H.M.: Dietary carbohydrate modification enhances insulin secretion in persons with the metabolic syndrome. $\mathrm{Am}$. J. Clin. Nutr., 82, 1218-1227, 2005.

[9] Jenkins, D.J., Wesson, V., Wolever, T.M., Jenkins, A.L., Kalmusky, J., Guidici, S., Csima, A., Josse, R.G., and Wong, G.S.: Wholemeal versus wholegrain breads: proportion of whole or cracked grain and the glycaemic response. $B M J$,
297, 958-960, 1988.

[10] Liljeberg, H.G., Granfeldt, Y.E., and Björck, I.M.: Products based on a high fiber barley genotype, but not on common barley or oats, lower postprandial glucose and insulin responses in healthy humans. J. Nutr., 126, 458-466, 1996.

[11] Cummings, D.E., Purnell, J.Q., Frayo, R.S., Schmidova, K., Wisse, B.E., and Weigle, D.S.: A preprandial rise in plasma ghrelin levels suggests a role in meal initiation in humans. Diabetes, 50, 1714-1719, 2001.

[12] Shiiya, T., Nakazato, M., Mizuta, M., Date, Y., Mondal, M.S., Tanaka, M., Nozoe, S., Hosoda, H., Kangawa, K., and Matsukura, S.: Plasma ghrelin levels in lean and obese humans and the effect of glucose on ghrelin secretion. $J$. Clin. Endocrinol. Metab., 87, 240-244, 2002.

[13] Cummings, D.E., Weigle, D.S., Frayo, R.S., Breen, P.A., Ma, M.K., Dellinger, E.P., and Purnell, J.Q.: Plasma ghrelin levels after diet-induced weight loss or gastric bypass surgery. $N$. Engl. J. Med., 346, 1623-1630, 2002.

[14] Hosoda, H., Kojima, M., Matsuo, H., and Kangawa, K.: Ghrelin and des-acyl ghrelin: two major forms of rat ghrelin peptide in gastrointestinal tissue. Biochem. Biophys. Res. Commun., 279, 909-913, 2000.

[15] Yoshimoto, A., Mori, K., Sugawara, A., Mukoyama, M., Yahata, K., Suganami, T., Takaya, K., Hosoda, H., Kojima, M., Kangawa, K., and Nakao, K.: Plasma ghrelin and desacyl ghrelin concentrations in renal failure. J. Am. Soc. Nephrol., 13, 2748-2752, 2002.

[16] Würsch, P. and Pi-Sunyer, F.X.: The role of viscous soluble fiber in the metabolic control of diabetes. A review with special emphasis on cereals rich in beta-glucan. Diabetes Care, 20, 1774-1780, 1997.

[17] Wolever, T.M.: Dietary carbohydrates and insulin action in humans. Br. J. Nutr., 83, Suppl. 1, S97-S102, 2000.

[18] Jenkins, D.J., Axelsen, M., Kendall, C.W., Augustin, L.S., Vuksan, V., and Smith, U.: Dietary fibre, lente carbohydrates and the insulin-resistant diseases. Br. J. Nutr., 83, Suppl. 1, S157-S163, 2000.

[19] Mathlouthi, N., Saulnier, L., Quemener, B., and Larbier, M.: Xylanase, beta-glucanase, and other side enzymatic activities have greater effects on the viscosity of several feedstuffs than xylanase and beta-glucanase used alone or in combination. $J$. Agric. Food Chem., 50, 5121-5127, 2002.

[20] Tappy, L., Gügolz, E., and Würsch, P.: Effects of breakfast cereals containing various amounts of beta-glucan fibers on plasma glucose and insulin responses in NIDDM subjects. Diabetes Care, 19, 831-834, 1996.

[21] Battilana, P., Ornstein, K., Minehira, K., Schwarz, J.M., Acheson, K., Schneiter, P., Burri, J., Jéquier, E., and Tappy, L.: Mechanisms of action of beta-glucan in postprandial glucose metabolism in healthy men. Eur. J. Clin. Nutr., 55, 327-333, 2001.

[22] Collier, G., McLean, A., and O'Dea, K.: Effect of co-ingestion of fat on the metabolic responses to slowly and rapidly absorbed carbohydrates. Diabetologia, 26, 50-54, 1984.

[23] Gulliford, M.C., Bicknell, E.J., and Scarpello, J.H.: Differential effect of protein and fat ingestion on blood glucose responses to high- and low-glycemic-index carbo- 
hydrates in noninsulin-dependent diabetic subjects. Am. J. Clin. Nutr., 50, 773-777, 1989.

[24] Henry, C.J., Lightowler, H.J., Kendall, F.L., and Storey, M.: The impact of the addition of toppings/fillings on the glycaemic response to commonly consumed carbohydrate foods. Eur. J. Clin. Nutr., 60, 763-769, 2006.

[25] Wolever, T.M., Vorster, H.H., Björck, I., Brand-Miller, J., Brighenti, F., Mann, J.I., Ramdath, D.D., Granfeldt, Y., Holt, S., Perry, T.L., Venter, C., and Wu, X.: Determination of the glycaemic index of foods: interlaboratory study. Eur. J. Clin. Nutr., 57, 475-482, 2003.

[26] Ito, Y., Mizukuchi, A., Kise, M., Aoto, H., Yamamoto, S., Yoshihara, R., and Yokoyama, J.: Postprandial blood glucose and insulin responses to pre-germinated brown rice in healthy subjects. J. Med. Invest., 52, 159-164, 2005.

[27] Elliott, R.M., Morgan, L.M., Tredger, J.A., Deacon, S., Wright, J., and Marks, V.: Glucagon-like peptide-1 (7-36) amide and glucose-dependent insulinotropic polypeptide secretion in response to nutrient ingestion in man: acute post-prandial and 24-h secretion patterns. J. Endocrinology, 138, 159-166, 1993.

[28] Weickert, M.O., Mohlig, M., Koebnick, C., Holst, J.J., Namsolleck, P., Ristow, M., Osterhoff, M., Rochlitz, H., Rudovich, N., Spranger, J., and Pfeiffer, A.F.: Impact of cereal fibre on glucose-regulating factors. Diabetologia, $\mathbf{4 8}$, 2343-2353, 2005.

[29] Ludwig, D.S.: The glycemic index: physiological mechanisms relating to obesity, diabetes, and cardiovascular disease. JAMA, 287, 2414-2423, 2002.

[30] Blom, W.A., Stafleu, A., de Graaf, C., Kok, F.J., Schaafsma, G., and Hendriks, H.F.: Ghrelin response to carbohydrateenriched breakfast is related to insulin. Am. J. Clin. Nutr., 81, 367-375, 2005.
[31] Möhlig, M., Koebnick, C., Weickert, M.O., Lueder, W., Otto, B., Steiniger, J., Twilfert, M., Meuser, F., Pfeiffer, A.F., and Zunft, H.J.: Arabinoxylan-enriched meal increases serum ghrelin levels in healthy humans. Horm. Metab. Res., 37, 303-308, 2005.

[32] Holt, S.H., Delargy, H.J., Lawton, C.L., and Blundell, J.E.: The effects of high-carbohydrate vs high-fat breakfasts on feelings of fullness and alertness, and subsequent food intake. Int. J. Food Sci. Nutr., 50, 13-28, 1999.

[33] Erdmann, J., Töpsch, R., Lippl, F., Gussmann, P., and Schusdziarra, V.: Postprandial response of plasma ghrelin levels to various test meals in relation to food intake, plasma insulin, and glucose. J. Clin. Endocrinol. Metab., 89, 30483054, 2004.

[34] Weickert, M.O., Spranger, J., Holst, J.J., Otto, B., Koebnick, C., Möhlig, M., and Pfeiffer, A.F.: Wheat-fibre-induced changes of postprandial peptide YY and ghrelin responses are not associated with acute alterations of satiety. Br. J. Nutr., 96, 795-798, 2006.

[35] Toshinai, K., Yamaguchi, H., Sun, Y., Smith, R.G., Yamanaka, A., Sakurai, T., Date, Y., Mondal, M.S., Shimbara, T., Kawagoe, T., Murakami, N., Miyazato, M., Kangawa, K., and Nakazato, M.: Des-acyl ghrelin induces food intake by a mechanism independent of the growth hormone secretagogue receptor. Endocrinology, 147, 2306-2314, 2006.

[36] Asakawa, A., Inui, A., Fujimiya, M., Sakamaki, R., Shinfuku, N., Ueta, Y., Meguid, M.M., and Kasuga, M.: Stomach regulates energy balance via acylated ghrelin and desacyl ghrelin. Gut, 54, 18-24, 2005.

[37] Chen, C.Y., Inui, A., Asakawa, A., Fujino, K., Kato, I., Chen, C.C., Ueno, N., and Fujimiya, M.: Des-acyl ghrelin acts by CRF type 2 receptors to disrupt fasted stomach motility in conscious rats. Gastroenterology, 129, 8-25, 2005. 